Check for updates

Cite this: RSC Adv., 2018, 8, 5372

DOI: $10.1039 / \mathrm{c} 8 \mathrm{ra90006j}$

www.rsc.org/advances

\section{Correction: Dipolar vinyl sulfur fluorescent dyes. Synthesis and photophysics of sulfide, sulfoxide and sulfone based $D-\pi-A$ compounds}

\author{
Matias Monçalves, ${ }^{a}$ Gabriel M. Zanotto, ${ }^{d}$ Josene M. Toldo, ${ }^{d}$ Daniel S. Rampon, ${ }^{c}$ \\ Paulo H. Schneider, ${ }^{b}$ Paulo F. B. Gonçalves, ${ }^{d}$ Fabiano S. Rodembusch ${ }^{\star b}$ \\ and Claudio C. Silveira*a
}

Correction for 'Dipolar vinyl sulfur fluorescent dyes. Synthesis and photophysics of sulfide, sulfoxide and sulfone based D- $\pi-A$ compounds' by Matias Monçalves et al., RSC Adv., 2017, 7, 8832-8842.

The authors regret that Table 2 was incorrectly formatted in the original manuscript showing two solvent columns. The correct table, with only one solvent column is presented below.

Table 2 Relevant photophysical data of the fluorescence spectra, where $\lambda_{\mathrm{em}}$ is the emission maxima $(\mathrm{nm}), \Delta \lambda_{\mathrm{ST}}$ is the Stokes' shift $\left(\mathrm{nm} \mathrm{cm}^{-1}\right.$ ), $\Delta \lambda_{\text {em }}$ is the solvatochromism in the excited state $\left(\mathrm{nm} \mathrm{cm}^{-1}\right)$ and $\Phi_{\mathrm{FL}}$ is the fluorescence quantum yield $(\%)$

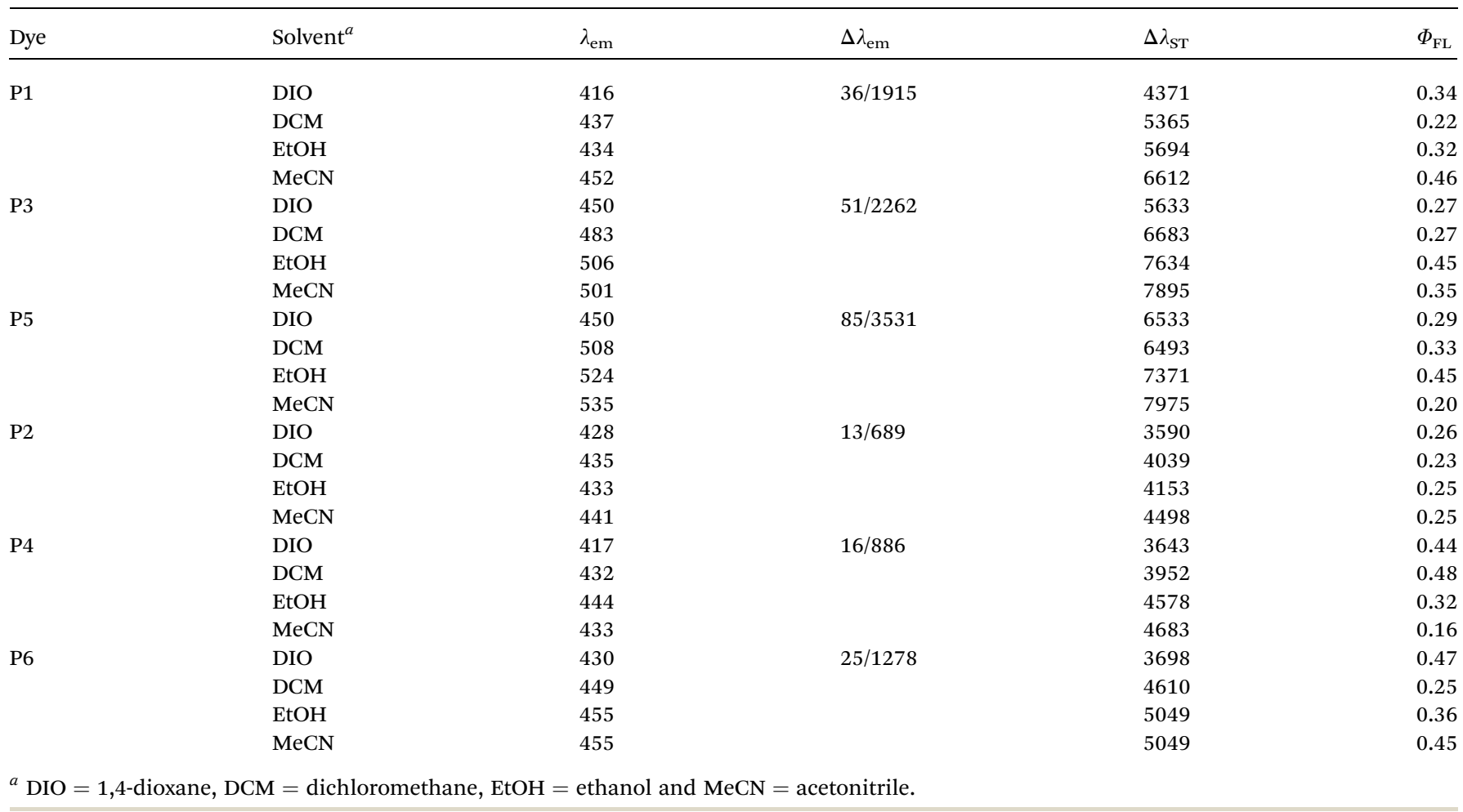

The Royal Society of Chemistry apologises for these errors and any consequent inconvenience to authors and readers.

${ }^{a}$ Departamento de Química, Universidade Federal de Santa Maria, CEP 97105-900, Santa Maria-RS, Brazil. E-mail: silveira@quimica.ufsm.br; Fax: +55 55 3220-8754

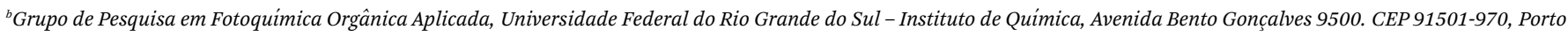
Alegre-RS, Brazil. E-mail: fabiano.rodembusch@ufrgs.br; Fax: +55 513308 7304; Tel: +55 5133087204 'Universidade Federal do Paraná, Departamento de Química, Laboratório de Polímeros e Catálise, CEP 81531-980, Curitiba, PR, Brazil

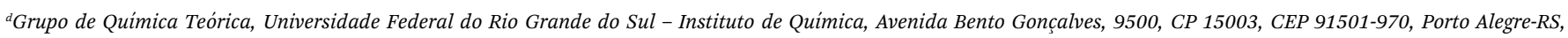
Brazil 